\title{
Cultivos celulares primarios de Lutzomyia shannoni (Diptera: psychodidae) y estudio cariológico preliminar de la especie
}

\author{
Felio J.Bello ${ }^{1}$, María E.Jiménez ${ }^{1}$, Cristina Ferro ${ }^{2}$
}

\begin{abstract}
Resumen
Con el propósito de obtener una línea celular de Lutzomyia shannoni (Dyar) para estudios de susceptibilidad viral y mantenimiento de parásitos, se iniciaron cultivos celulares primarios de esta especie, vectora del virus de la estomatitis vesicular en los Estados Unidos y vectora sospechosa de leishmaniasis cutánea en las Américas. A partir de embriones y larvas neonatas del flebotomíneo, se realizaron explantes de tejidos embrionarios en el medio MM/VP12, suplementado con $20 \%$ de suero fetal bovino y una mezcla de antibiótico y antimicótico, los cuales fueron incubados a una temperatura promedio de $28^{\circ} \mathrm{C}$, sin atmósfera de $\mathrm{CO}_{2}$. El crecimiento celular comenzó en un período de 85 a 88 días después de efectuadas las siembras, mediante la presencia de vesículas compuestas de células epitelioides, flotando en el medio o adheridas a pequeños fragmentos de tejidos con células en división. Previa estimulación mecánica de los cultivos, se incrementó la proliferación celular a la semana siguiente de efectuado el procedimiento; sin embargo, el proceso mitótico de las células fue lento, similar al desarrollado con Lu. longipalpis, pero diferente a los cultivos celulares derivados de mosquitos. La formación de colonias individuales, dispersas en la superficie del frasco de cultivo, se observó a los 90 días de incubación, las cuales posteriormente evolucionaron a una monocapa semiconfluente. La morfología celular fue heterogénea con predominio de tipos epitelioides. Mediante la técnica de squash, se obtuvo el cariotipo de la especie, cuyo número diploide de cromosomas fue de 8 , derivados de tejidos cerebrales de larvas de IV estadio.
\end{abstract}

\section{Summary}

To obtain a Lutzomyia shannoni (Dyar) cell line for viral susceptibility studies and parasite maintainance, primary cell cultures of this species were initiated. This species is a vector for vesicular stomatitis virus in the United States and a suspected vector of cutaneous leishmaniasis in the Americas. Starting with embryos and phlebotominae neonate larvae, embryonic tissue explants in a MM/VP12 medium were carried out. After being supplemented with $20 \%$ fetal bovine serum and an antibiotic and antimycotic mixture, they were incubated at $28^{\circ} \mathrm{C}$ in a non- $\mathrm{CO}_{2}$ environment.

Cell growth began 85 to 88 days after the cultures were initiated due to epithelial cell vesicle presence; these were floating in the media or adhered to small fragments of tis-

' Laboratorio de Investigaciones en Entomología, Biología Celular y Genética, Universidad de La Salle, Santa Fe de Bogotá.

${ }^{2}$ Laboratorio de Entomología, Instituto Nacional de Salud, Santa Fe de Bogotá. 
sue with divided cells. Following mechanical stimulation of the cultures, cell proliferation increased in the week following the procedure; however, cell mitotic process was slow, similar to that developed with $L u$. longipalpis, but different to cell cultures derived from mosquitoes. The formation of individual colonies, dispersed on the surface of the culture flasks, was observed 90 days after incubation; these later evolved to a semiconfluent monolayer. The cellular morphology was heterogeneous with predominant epithelial types. Using the squash technique, this species' karyotype was obtained; the number of diploid chromosomes was 8 , derived from fourth-instar larvae brain tissue.

Lutzomyia shannoni (Dyar) es un flebotomíneo de importancia médica por ser vector del virus de la estomatitis vesicular en los Estados Unidos y sospechoso vector de leishmaniasis cutánea americana $(1,2)$. Su distribución geográfica es amplia en las Américas, desde el norte de Argentina hasta el noreste de los Estados Unidos. En Colombia, se ha registrado en casi todo el país desde el nivel del mar hasta $1.000 \mathrm{~m}$ de altitud (3).

Los cultivos celulares de insectos son importantes en estudios fisiológicos, bioquímicos, genéticos y moleculares e, igualmente, son útiles como sustratos para el mantenimiento de parásitos y para el aislamiento e identificación de arbovirus (4-8). El establecimiento de líneas celulares del género Lutzomyia cobra especial importancia debido a las dificultades que implica obtener colonias de estas especies en el laboratorio y, también, por el tiempo relativamente prolongado (superior a 40 días) que emplean los flebotomíneos en su ciclo de vida (9). En contraste, los cultivos celulares derivados de estos insectos pueden crecer en un medio definido, ocupan poco espacio, requieren pocos controles ambientales $y$, más importante aún, se pueden mantener indefinidamente en nitrógeno líquido (10).

Los cultivos primarios se obtienen de explantes de tejidos embrionarios, de fragmentos de larvas neonatas y de secciones de gónadas, a partir de los cuales, las células migran y se adhieren a un sustrato artificial. Por separación mecánica o enzimática de los tejidos, se produce una suspensión de células, las cuales eventualmente formarán una monocapa $(4,5,11-13)$.
Un número significativo de líneas celulares de insectos, orden Diptera se ha establecido desde Grace 1966 (14) hasta nuestros días, correspondientes principalmente a la familia Culicidae $(13,15-23)$; sin embargo, en flebótomos, solo se ha establecido una línea celular de la especie Lu. longipalpis, cepa Brasil (24).

En este trabajo, se describe por primera vez el proceso de iniciación de cultivos celulares primarios de Lu. shannoni a partir de huevos embrionados y larvas neonatas; se caracte-rizan los tipos morfológicos celulares, se establecen los parámetros físicos, ambientales y nutricionales necesarios para la adaptación y el crecimiento celular. Igualmente, se efectúa un estudio cariológico preliminar de la especie, utilizando para tal efecto, larvas de IV estadio, mediante la técnica de squash o aplastamiento del tejido.

\section{Materiales y métodos}

Material biológico. Se utilizaron huevos embrionados y larvas neonatas de Lu. shannoni, procedentes de la colonia establecida en el Laboratorio de Entomología del Instituto Nacional de Salud de Santa Fe de Bogotá, Colombia, la cual se originó de ejemplares recolectados en el municipio del Carmen de Bolívar (Bolívar, Colombia) en octubre de 1992 (Datos sin publicar, Laboratorio de Entomología, INS).

Medios de cultivos. Se emplearon los siguientes medios: MM (25), VP12 (16), MK (26), MM/VP12 (16), MK/VP12 (17). Estos fueron suplementados con suero fetal bovino al $20 \%$, antibiótico (mezcla de penicilina $100 \mathrm{U} /$ 
$\mathrm{mL}$ y estreptomicina $100 \mathrm{U} / \mathrm{ml}$ ) y antimicóticos (anfotericina B).

Esterilización de las muestras. Huevos embrionados de 8, 9 y 10 días de incubación, mantenidos en recipientes cuyo fondo estaba recubierto de yeso dental, fueron recogidos en un tubo de ensayo mediante presión del agua sobre la superficie de las tazas, al retirar el líquido se adicionó hipoclorito de sodio al 1,6\% el cual se dejó actuar sobre la superficie de los huevos, con agitación continua durante 19 minutos, previa centrifugación y descarte del sobrenadante se adicionó etanol al $70 \%$, repitiéndose el procedimiento anterior. Finalmente, se lavaron los huevos tres veces con agua destilada estéril (22).

Iniciación de cultivos primarios. Una vez efectuada la esterilización de los huevos embrionados, se realizó un homogenizado en una pequeña cantidad de medio enriquecido. La suspensión resultante se llevó a un frasco de plástico para cultivo de tejidos de $25 \mathrm{~cm}^{2}$ que contenía $5 \mathrm{~mL}$ del medio de crecimiento; finalmente, se incubó $\mathrm{a} \pm 28^{\circ} \mathrm{C}$, sin atmósfera de $\mathrm{CO}_{2}$. La observación diaria de los cultivos se efectuó con la ayuda de un microscopio invertido marca Olympus CK-2.
Preparación de cromosomas micóticos. Se utilizaron larvas de IV estadio, las cuales fueron colocadas en solución de colchicina al 0,1\% durante 6 horas. La disección de la larva se efectuó en presencia del reactivo de Belar; el cerebro fue removido $y$, luego, trasladado a una laminilla a la que previamente se le colocó una gota de Carnoy (metanol-ácido acético 3:1) en donde se dejó por 10 minutos; se adicionó a la preparación una gota de colorante orceína-lactoacética durante 20 minutos. La lámina se colocó encima del micropreparado y se procedió a efectuar el squash (27) (cuadro 1).

\section{Resultados}

Iniciación de cultivos primarios. El crecimiento celular de $L u$. shannoni se inició en un rango de 85 a 88 días, después que los embriones fueron explantados al interior de algunos frascos con medio de cultivo MM/VP12, los cuales permanecieron incubados a $28^{\circ} \mathrm{C}$; en el transcurso de dicho tiempo, cada 15 días se le adicionaron a los frascos de cultivo $5 \mathrm{~mL}$ de medio fresco. Alrededor de los fragmentos de tejidos adheridos a la superficie de los frascos, empezó el proceso de crecimiento y división celular; sin embargo, esta situación no fue uniforme, algunas colonias celulares lograron

Cuadro 1. Resumen del proceso en la iniciación de cultivos celulares primarios.

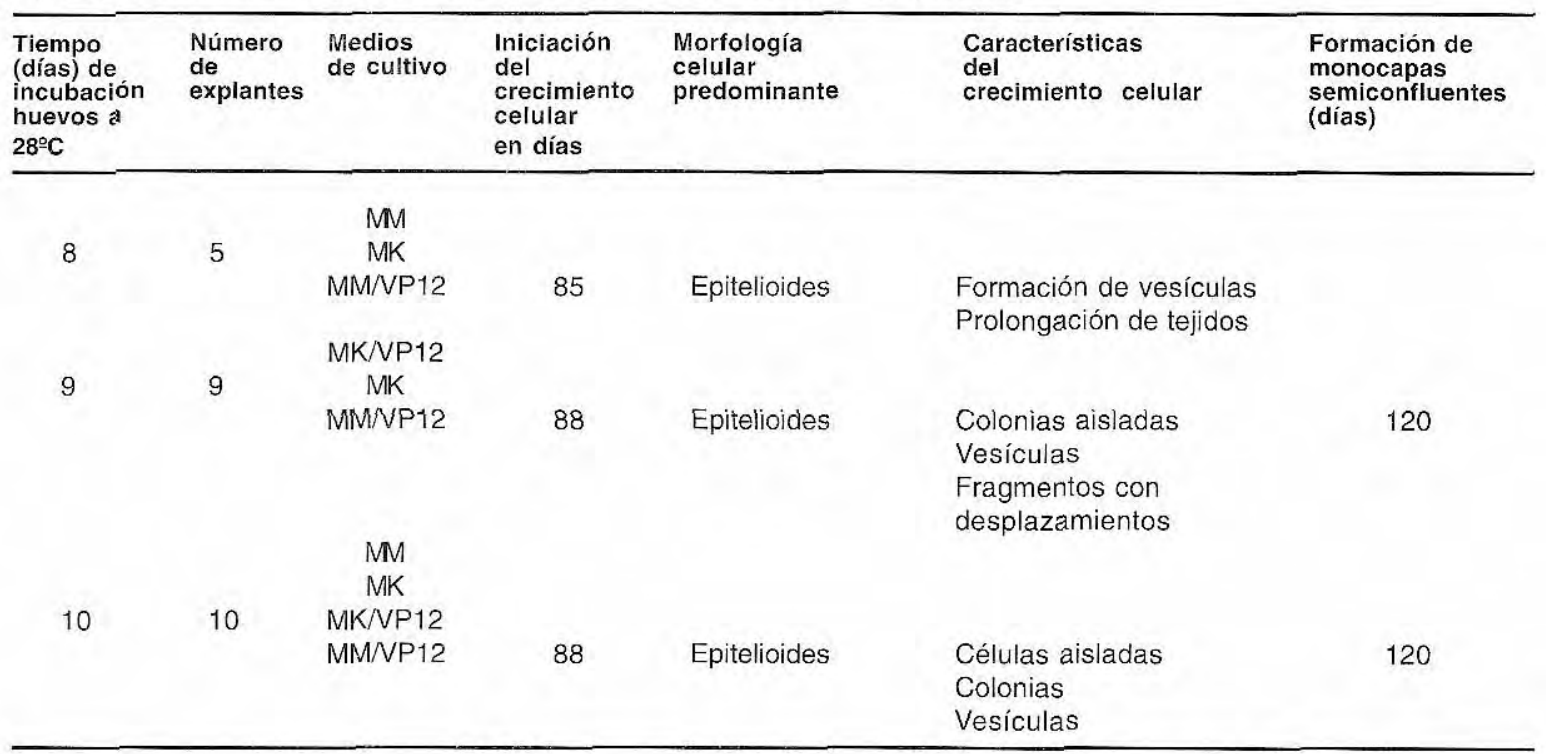


avanzar y ocupar espacios considerables en el sustrato, mientras que otros se dividieron lentamente, detuvieron el crecimiento y degeneraron. La presencia de un gran número de vesículas compuestas de células epitelioides (figura 1) fue una constante alrededor de los fragmentos de iejidos o fiotando en el medio de cultivo después de 90 días de incubación; al transcurrir los días aumentaron en número y tamaño, pero, luego de pipetear vigorosamente el medio de cultivo y centrifugar, un gran número de células lograron adherirse y crecer en la superficie de los frascos después de haber sido resuspendidos y sembrados con medio fresco.

La monocapa semiconfluente se observó a los 120 días después de haberse iniciado el proceso para la obtención de cultivos primarios. E: óptimo rango de $\mathrm{pH}$ para el crecimiento celular fue 6,8 a 7,0 , los huevos embrionados que mejores resultados produjeron en la iniciación de cultivos primarios fueron los de 8 a
10 días, después de la oviposición. No se observó crecimiento celular en los frascos que individualmente contenían los medios MM, MK, VP12 y MK/VP12. En el cuadro 1 se compendia el proceso de la iniciación de los cultivos celulares primarios.

Morfología celular. Los cultivos celulares primarios de Lu. shannoni se componían inicialmente de una heterogénea población celular, consistente de formas esféricas, alargadas, irreguiares y, ocasionalmente, gigantes. Sin embargo, en la monocapa semiconfluente el tipo dominante fue el epitelioide (figura 2).

Cariotipo. Las metafases obtenidas de las células de cerebro de Lu. shannoni, exhibieron 4 pares de cromosomas como número diploide de la especie con un número fundamental de 16 (figura 3). Los pares cromosómicos se denominaron 1,2, 3 y 4 en orden ascendente de tamaño.

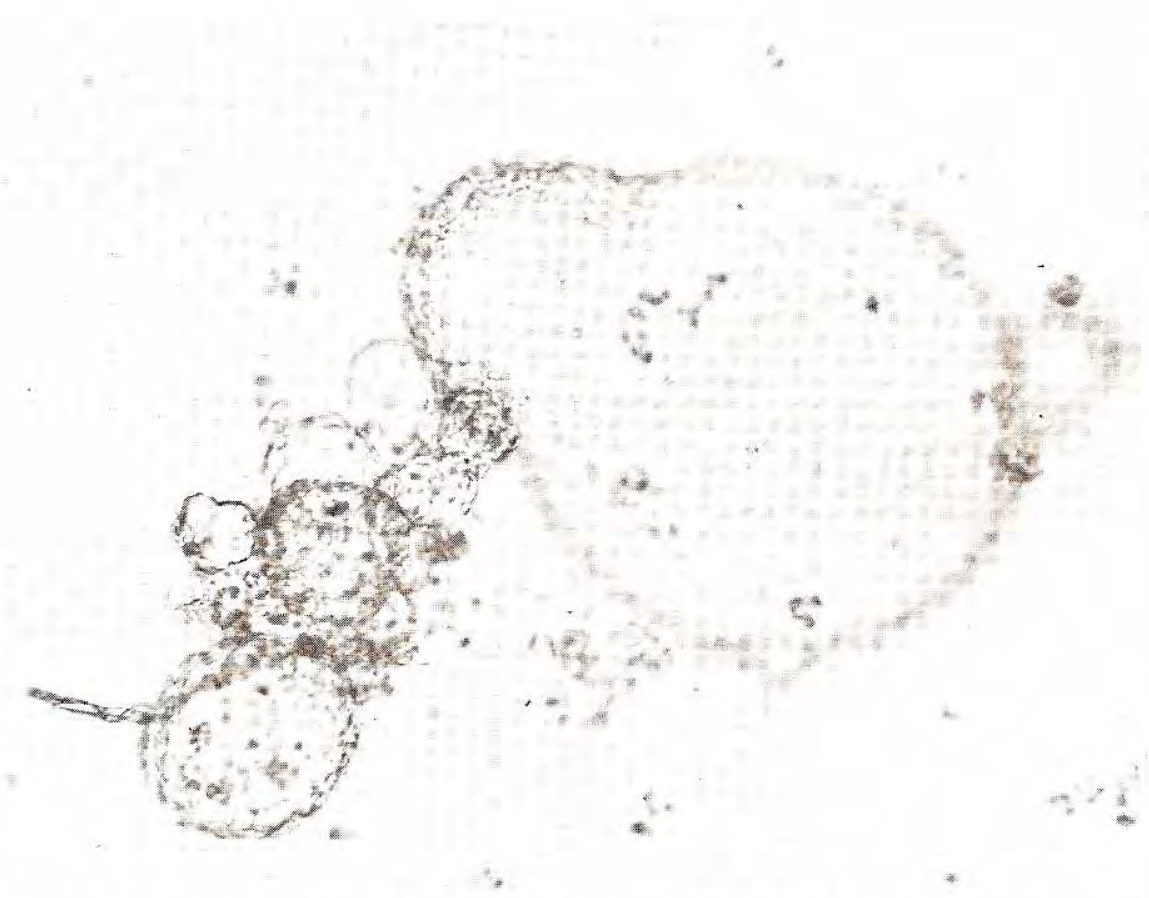

Figura 1. Vesículas compuestas de células epitelioides flotando en el medio de crecimiento. 


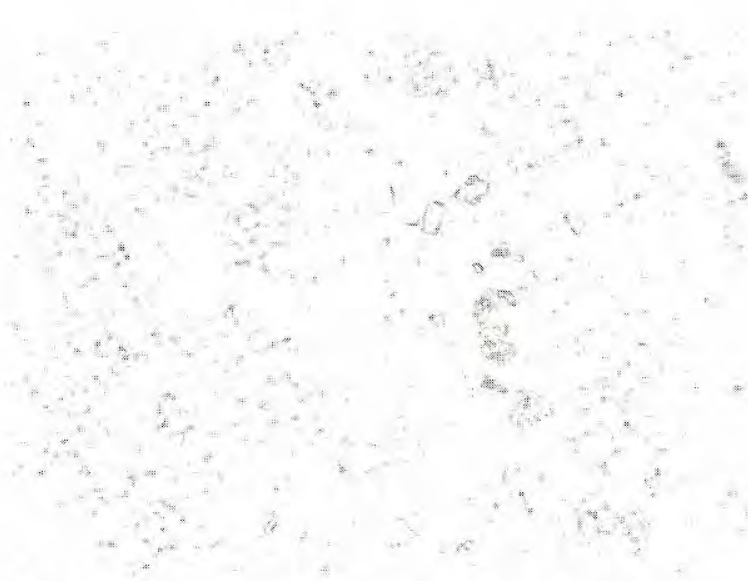

Figura 2. Monocapa semiconfluente de Lutzomyia con células predominantemente epitelioides.

\section{Discusión}

La iniciación del crecimiento celular de los cultivos primarios de Lu. shannoni, a partir de fragmentos de tejidos embrionarios, en forma de colonias firmemente adheridas a la superficie del frasco, fue semejante a lo observado con los cultivos de Lu. longipalpis $(24,28)$; sin embargo, el desplazamiento de las células en etapas tempranas de proliferación en la especie shannoni, se produjo como una prolongación del tejido y no como células sueltas, lo que en cierta forma imposibilitó en esta fase una nítida diferenciación de la morfología celular. La conexión de las células con el tejido de origen se interrumpió en etapas posteriores del crecimiento, tomando diferentes direcciones en la migración a través del sustrato y adquiriendo también la tipificación de sus formas.

A pesar de que la población celular en los cultivos primarios fue variada, hubo después de un incremento en la división, una tendencia a adquirir formas epitelioides en la monocapa semiconfluente, a diferencia de los cultivos celulares primarios de Lu. longipalpis (28), en donde se configuraron dos clases de monocapas: unas predominantemente epitelioides y otras de tipo fibroblástico.

El medio de cultivo en donde las células embrionarias de $L u$. shannoni lograron adaptarse, crecer y proliferar hasta constituir los cultivos celulares primarios fue el MM/VP12, lo

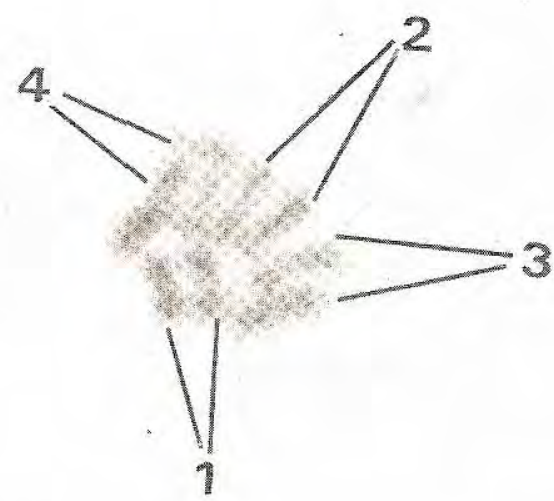

Figura 3. Cromosomas mitóticos de cerebro de larvas de IV estadio de Lutzomyia shannoni.

que indica necesariamente, que las condiciones nutritivas óptimas en calidad y cantidad fueron aportadas por este medio. No ocurrió lo mismo en los medios MM, VP12, MK y MKNVP12 que, a pesar de tener las mismas condiciones de $\mathrm{pH}$, osmolaridad $e$ incubarse a igual temperatura, los tejidos embrionarios explantados no evidenciaron crecimiento celular.

El tiempo empleado por las células de los tejidos embrionarios de Lu. shannoni para iniciar el crecimiento fue diferente con respecto al empleado por Lu. longipalpis (28), ya que las primeras utilizaron, en promedio, 88 días, en tanto que en $\mathrm{Lu}$. shannoni el rango estuvo entre 25 y 27 días. Esta situación puede explicarse, en parte, por las adaptaciones distintas que posiblemente presentaron las células embrionarias de ambos insectos a las condiciones físicas, ambientales y nutricionales utilizadas. El tiempo de incubación (8 a 10 días) en el cual los huevos produjeron mejores resultados en la iniciación de cultivos primarios, en el presente trabajo, resultó también diferente al compararlo con la especie de Lu. longipalpis $(24,28)$, cuyo rango de incubación fue de 3 a 6 días, lo cual indica que en los tejidos embrionarios de Lu. shannoni, el proceso de adaptación al medio fue más prolongado y probablemente las células que iniciaron el crecimiento se derivaron de etapas más avanzadas en la diferenciación. 
La técnica de squash o aplastamiento del tejido utilizada en el presente trabajo para la preparación de cromosomas, ratifica el hecho conocido sobre la resolución, morfología y continuidad en la compactación de la cromatina en cada uno de los pares homólogos, que resultan de menor calidad, comparados con las preparaciones obtenidas con las técnicas de secado al aire y cultivos celulares (29), en donde se logran mejores resoluciones, clara separación de los homólogos y una nítida diferenciación de las estructuras primarias. El número cromosómico diploide de 8 en $L U$. shannoni coincide con otras especies de flebótomos; sin embargo, de acuerdo con estudios previos, se ha podido demostrar que existe un rango del número cromosómico diploide en estos insectos, que va de $2 n=6$ a $2 \mathrm{n}=10(30,31)$.

\section{Agradecimientos}

A Colciencias, a la Universidad de La Salle y al Instituto Nacional de Salud por la financiación del presente trabajo.

\section{Referencias}

1. Comer JA, Tesh RB, Modi GB, Corn JL, Nettles VF. Vesicular stomatitis virus, New Jersey serotype: replication and transmission by $\mathrm{Lu}$. shannoni (Diptera: Psychodidae). Am J Trop Med Hyg 1990;42:483-90.

2. Comer JA, Stallknecht DE, Corn JL, Netîles VF. Lu. shannoni (Diptera: Psychodidae): a biological vector of the New Jersey serotype of vesicular stomatitis virus. Ossabaw Island Georgia. Parasitol 1991;33: 151-8.

3. Osorno E, Morales A. Fhlecotoninae de Colombia (Diptera: Psychodidae). IX.Distribucion geográfica de especies de Brumptomyia Franca y Parrot, 1921 y Lutzomyia Franca, 1924 encontrados en Colombia, S. A. Revista de la Academia Colombiana de Ciencias Exactas, Físicas y Naturales 1972;14:45-68.

4. Grace TDC. Development of insect cell culture. In: Maramorosch K, Matsuhashi J, editors. Invertebrate cell culture, aplications. New York: Acadiemic Press; 1982:1-8.

5. Igarashi A. Isolation of a Singh's Aedes albopictus cell clones sensitive to dengue and chikungunya $\mathrm{Vi}$ ruses. J Gen Virol 1978;40:531-44.

6. Kuno G, Gubler DJ, Velez M, Oliver A. Comparative sensitivity of three mosquito cell line for isolation of dengue viruses. Bull WHO 1985;63:279-86.
7. Maramorosch $\mathrm{K}$, editor. Biotechnology in invertebrate pathology cell culture. San Diego: Academic Press; 1987.

8. Sieburth PH, Maruniak JE. Growth characteristics of a continuous cell lines from the velvetbeau caterpillar. Anticarsia gemmatalais Hubner (Lepidoptera: noctuidae). In Vitro Cell Dev Biol 1988;24:195-8.

9. Killick-Kendrick R, Maroli M, Killick-Kendrick M. Bibliography on the colonization of phlebotominae sand-fly. Parasitol 1991;33(Suppl.1):321-33.

10. Munstermann L. Manual for mosquito rearing and experimental techniques. Am Mosquito Contr Assoc 1994:5:1-2.

11. Freshney RI. Culture of animal cells. A manual of basic techniques. New York: Wiley Liss; 1987.

12. Igarashi A. Mosquito cell culture and study of arthropod-borne togaviruses. Ad Virus Res 1985;30:21-42.

13. Singh KRP. Cell culture derived from larvae of Ae. albopictus (Skuse) and Ae. aegypti (L). Curr Sci 1967; 36:506-8.

14. Grace TDC. Establishment of a line of mosquito Ae. aegypti L, cells grown in vitro. Nature (London) 1966; 211:366-7.

15. Schneider I. Establishment of three diploid cell lines of Anopheles stephensi (Diptera: Culicidae). J Cell Biol 1969;42:603-6.

16. Varma MGR, Pudney $M$. The growth and serial passage of cell ines from Ae. aegypti $(L)$ larvae in different medium. J Med Entomol 1969;432-39.

17.Varma MGR, Pudney M. An. stephensi V. mysacaranresis: establishment of a larval cell line (Mosq. 43). Exp Parasitol 1971;29:7-12.

18. Cahoon BE, Hardy JL, Reeves WC. Initiation and characterization of a diploid cell line from larval tissues of Aedes dorsalis (Meigen). In vitro 1978;14:255-60.

19. Tesh RB. Establishment of two cell lines from the mosquito Toxorhynchites amboinensis (Diptera: Culicidae) and their susceptibility to infection with arboviruses. J Med Entomol 1980;17:338-43.

20. Rowley WA, Dorsey DC, Knowless MA. The replication of two californica serogroup viruses in cell line from the mosquito Aedes triseriatus (Diptera: Culicidae). J Med Entomol 1984;21:501-6.

21. Oelofsen MJ, Gerke A, Smith MS, De K van Der Linden TC. Establishment and characterization of a cell line from the mosquito Culex (Culex) theileri (Diptera: Culicidae) and its susceptibility to infection with arboviruses. J Med Entomol 1990;27:939-44.

22. Bello FJ, Boshell J, Rey G, Morales A, Olano V. Initiation of primary cell cultures from embryos of the mosquitoes An. albimanus and Ae.taeniorhynchus (Diptera: Culicidae). Mem Do Inst Oswaldo Cruz 1995; 90:547-51. 
23. Bello FJ, Brochero H, Boshell J, Olano V, Rey G. Establishment and characterization of a cell line from the mosquito Anophles albimanus (Diptera: Culicidae). Mem Do Inst Oswaldo Cruz 1997;92:123-8.

24. Tesh RB, Modi GB. Development of a continuous cell line form the sandfly Lu.longipalpis (Diptera: Psychodidae) and its susceptibility to infection with arboviruses. J Med Entomol 1983;20:199-202.

25. Mitsuhashi J, Maramorosch K. Leafhoper and tissue culture: embrionyc, nymphal and imaginal tissue from aseptic insects. Contrib Boyce Thompson Inst 1964;22:435-60.

26. Kitamura S. Establishment of a cell line from Culex mosquito. Kobe J Med Sci 1970;16:41-50.

27. French WL, Baker RH, Kitzmiller JB. Preparation of mosquito chromosomes. Mosquito News 1962;22: 377-84.
28. Bello FJ, Rey G, Jiménez ME, Ferro C, Munstermann L. Iniciación de cultivos celulares primarios de Lu. longipalpis (Diptera: Psychodidae). Rev Diógenes 1996;3:155-66.

29. Bello FJ, Olano V, Morales A, Boshell J, Rey G, Durán $F$. Evaluación de tres técnicas citogenéticas diferentes en los estudios morfométricos del cariotipo de Aedes taeniorhynchus (Diptera: Culicidae). Biomédica 1995; 15:109-15.

30. Kreutzer RD, Modi GD, Tesh RB, Young DG. Brain cell karyotypes of six species of new and Old World sandflies (Diptera: Psychodidae). J Med Entomol 1987; 24:609-12.

31. Kreutzer RD, Morales A, Cura E, Ferro C, Young DG. Brain cell karyotypes of six new world sandflies (Diptera: Psychodidae). J Am Mosquito Contr Assoc 1988;4:453-6. 